\title{
Mapping surface-water area using time series landsat imagery on Google Earth Engine: a case study of Telangana, India
}

\author{
P. D. Sreekanth*, P. Krishnan, N. H. Rao, S. K. Soam and Ch. Srinivasarao \\ ICAR-National Academy of Agricultural Research Management, Rajendra Nagar, Hyderabad 500 030, India
}

\begin{abstract}
The extent of surface-water spread influences the hydrogeology and ecology of waterbodies. Remote sensing technology provides spatial and temporal datasets which aid in mapping the dynamics of surface waterbodies at the regional and global scale. In the present study, temporal changes in the surface area of waterbodies in Telangana, India, were monitored using indices like normalized difference vegetation index, normalized difference water index and modified NDWI and machine learning algorithms like a random forest using Landsat-8 data. Google Earth Engine cloud computing platform was used for processing earth observation data, based on the time series images of Landsat and compared with real-time groundwater levels. The results showed a significant increase $(P<0.01)$ in both surface-water area and groundwater levels in Telangana, especially after 2015, which we hypothesize could be due to the specialized water conservation project being implemented by the Government of Telangana since 2015 .
\end{abstract}

Keywords: Cloud computing platform, groundwater level, machine learning algorithms, remote sensing, surface area, waterbodies.

SURFACE water is a significant component in the hydrological cycle. It is one of the most important resources for domestic use, irrigation purposes and industrial and social development ${ }^{1-3}$. The development of surface waterbodies, which change their shape and course of flow with space and time, due to hydrological processes and also its human-induced factors, depends on rainfall intensity and duration, particularly in the semiarid regions ${ }^{4}$. These changes can be influenced by socio-economic development and ecosystem of the area. Therefore, surface-water information plays an important role in socio-economic development and assessment of risk due to floods, their management and mitigation ${ }^{5}$.

Remote sensing (RS) aids in monitoring temporal changes in the extent of surface waterbodies ${ }^{6}$. RS datasets provide the physical features and spatio-temporal variations of surface waterbodies at various spatial scales at

\footnotetext{
*For correspondence. (e-mail: sreekanth@naarm.org.in)
}

regular time intervals ${ }^{7-10}$. Normalized difference vegetation index (NDVI) is used to categorize floods and surface water, but does not provide details directly about surface water ${ }^{11,12}$. Normalized difference water index (NDWI) and modified NDWI (mNDWI) have been the most useful indices to identify waterbodies and their surface-water spread over the years ${ }^{13-16}$.

The assessment of surface-water availability and its spatio-temporal distribution is of paramount importance for planning crop cultivation activities, real-time monitoring and managing irrigation operations in many regions of the world ${ }^{17,18}$. Recently, Anand et al. ${ }^{15,19}$ explained the surface-water spread assessment frameworks which are based on NDWI, for planning fish culture activities in inland lentic waterbodies such as reservoirs, lakes and ponds. The spatio-temporal surface-water assessment also applied for the monitoring and management of natural water resources, prediction of ecosystem health and prevention of water-related disaster uses Google Earth Engine (GEE) for near real-time monitoring of flood events, as it allows for rapid deployment of the algorithm ${ }^{20-23}$.

The recent census of minor irrigation sources in Telangana, India, revealed the presence of 46,531 such sources, like tanks (percolation/forest), private kuntas, anicuts and check dams. There were also about 16 major and 38 medium irrigation projects (both completed and ongoing) in the $\operatorname{state}^{24}$. The present study demonstrates the use of GEE algorithm-based rapid surface-water estimation technique to assess the district-wise seasonal water spread availability over the years in Telangana. The study results could aid in planning cropping patterns, fish culture activities and for evaluating the effectiveness of water-body restoration projects and other watershed management strategies.

\section{Materials and methods}

\section{Study area}

Telangana is located between $16^{\circ} 30^{\prime}-18^{\circ} 20^{\prime} \mathrm{N}$ lat. and $77^{\circ} 30^{\prime}-79^{\circ} 30^{\prime} \mathrm{E}$ long. in the southern region of India covering 33 districts and with a total area of about 112,077 sq. km (ref. 25). Geographically, the state falls in 


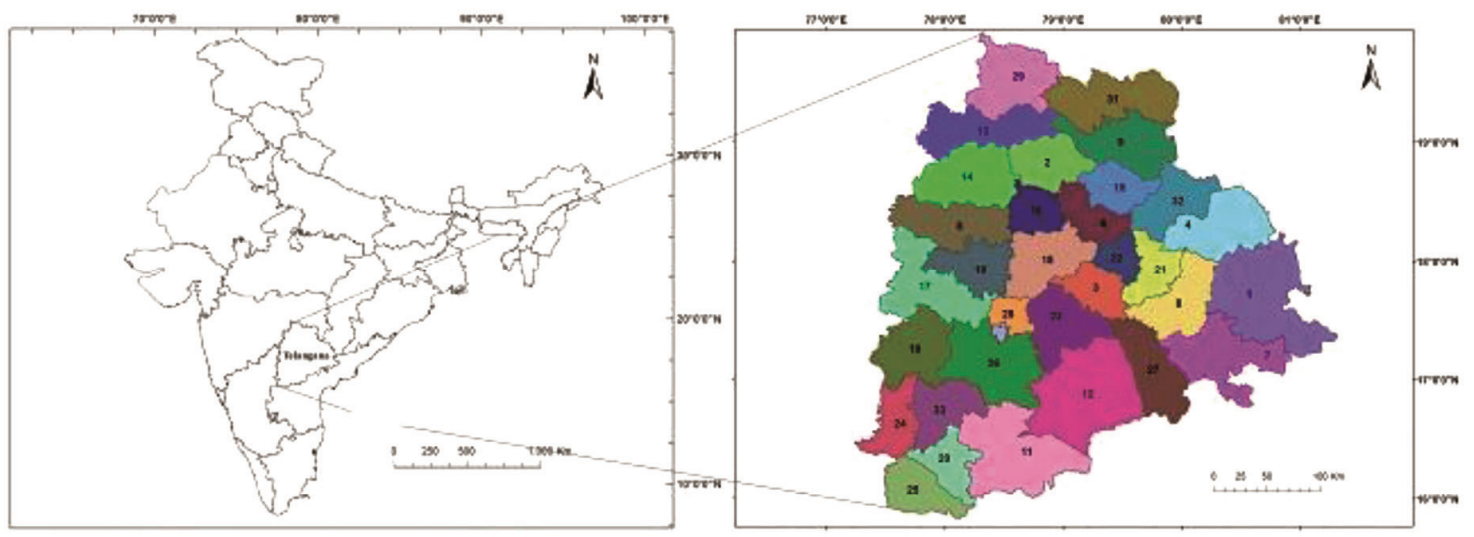

Figure 1. Map showing the study area. 1, Bhadradri Kothagudem; 2, Jagtial; 3, Jangoan; 4, Mulugu; 5, Kamareddy; 6, Karimnagar; 7, Khammam; 8, Mohabubadad; 9, Mancherial; 10, Medak; 11, Nagarkurnool; 12, Nalgonda; 13, Nirmal; 14, Nizamabad; 15, Peddapalli; 16, Rajanna Sircilla; 17, Sangareddy; 18, Siddipet; 19, Vikarabad; 20, Wanaparthy; 21, Warangal rural; 22, Warangal Urban; 23, Yadadri huvanagiri; 24, Narayanpet; 25, Jogulamba Gadwal; 26, Rangareddy; 27, Suryapet; 28, Medchal Malkjgiri; 29, Adilabad; 30, Hyderabad; 31, Kumurambheem Asifabad; 32, Jayashankar Bhupalpally and 33, Mahabubnagar.

Table 1. Specification of satellite data used in the present study

\begin{tabular}{|c|c|c|c|c|c|c|}
\hline Study period & Satellite & Sensor & Interval & Resolution (m) & Image count & Wavelength $(\mu \mathrm{m})$ \\
\hline 2013-2019 & Landsat 8 & OLI & 16 days & 30 & 874 & $\begin{array}{l}\text { Band 1: } 0.43-0.45 \\
\text { Band 2: } 0.45-0.51 \\
\text { Band 3: } 0.53-0.59 \\
\text { Band 4: } 0.64-0.67 \\
\text { Band 5: } 0.85-0.88 \\
\text { Band 6: } 1.57-1.65 \\
\text { Band 7: } 2.11-2.29 \\
\text { Band 8: } 0.50-0.68 \\
\text { Band 9: } 1.36-1.38\end{array}$ \\
\hline
\end{tabular}

semiarid zone of the Deccan Plateau and has a hot and dry climate. The mean maximum and minimum temperatures vary from $40^{\circ} \mathrm{C}$ to $43^{\circ} \mathrm{C}$ and $13^{\circ} \mathrm{C}$ to $17^{\circ} \mathrm{C}$ respectively. The state receives an average annual rainfall of $906 \mathrm{~mm}$, most of which is during the southwest monsoon. A significant proportion (73.5\%) of the geographical area of the state is covered by the basins of two major rivers, viz. Godavari and Krishna ${ }^{26}$. Figure 1 shows the study area.

\section{Data description}

For analysing surface water of Telangana, GEE - a webbased cloud computing platform, which currently provides over 11 petabytes of earth observation data was used $^{27}$. GEE offers various advantages - access to large volume of processed remote sensing image data and dedicated cloud storage; simple and rapid programming and graphic interface and possibility for assessing surfacewater dynamics at the planetary scale for a prolonged period $^{21,23}$. A total of 874 top-of-atmosphere (TOA) scenes of Landsat 8 with $30 \mathrm{~m}$ resolution data were acquired during the monsoon and post-monsoon seasons for the period 2013-2019 in the study area following United States Geological Survey (USGS) (Table 1) ${ }^{28}$.

Since there was major deviation in surface waterbodies within a given year, plentiful spread data about surface waterbodies were obtained subsequently from Landsat images every year during July to December. Every 16 days, the Landsat covers the same spot on the earth, and provides approximately 12 images over a six-month period. The collection of images represents those taken over a period of time and each pixel on the map is resulting from a pile of pixels. In this study, quality mosaic method was adopted to extract greenest and wettest pixel from the image collection, wherein the assortment with the greatest incentive for the predetermined band and in this technique sets every pixel in the composite.

\section{Estimation of surface-water cover}

A schematic diagram in Figure 2 shows the methodology for surface-water extraction. It mainly consists of $\mathrm{NDVI}^{29}, \mathrm{NDWI}^{13}$ and $\mathrm{mNDWI}^{30}$ from various bands of images and erases clear non-water pixels by NDVI, NDWI and mNDWI veiling methodology and further concentrates surface-water pixels. The indices were calculated using eqs (1)-(3) as follows ${ }^{31}$

$$
\mathrm{NDVI}=\frac{(\mathrm{NIR}-\mathrm{red})}{(\mathrm{NIR}+\mathrm{red})}
$$




$$
\begin{aligned}
& \text { NDWI }=\frac{(\text { Green }- \text { NIR })}{(\text { Green }+ \text { NIR })}, \\
& \text { mNDWI }=\frac{(\text { Green }- \text { SWIR } 1)}{(\text { Green }+ \text { SWIR } 1)},
\end{aligned}
$$

where NIR is a value of near infrared band, red and green are the value of red and green band respectively; SWIR1 is a value of shortwave Infrared band.

NDWI and mNDWI are employed to maximize and minimize the reflectance of water features using green wavelengths and NIR or SWIR1, and the high reflectance of NIR or SWIR1 is used for delineating soil features and vegetation of the area. Therefore, the water feature values are more significant in the mNDWI and NDWI images $^{32,33}$. However, since the water pixels have higher NDWI and lower NDVI values, an initial surface-water map can be obtained by concealing all pixels that have higher NDVI and lower NDWI values. In this study, the threshold values of NDVI $(\geq 0.2)$ and NDWI $(\leq-0.3)$ were set to remove most non-water pixels, and to

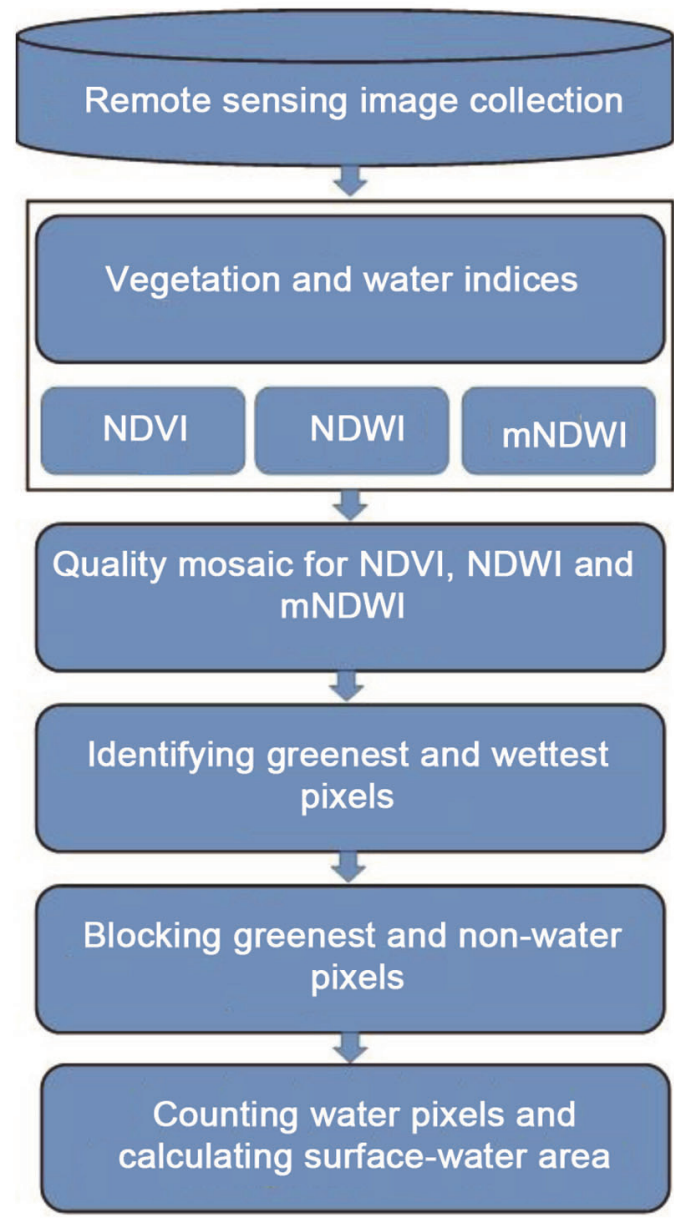

Figure 2. Schematic for the surface-water calculation performed in the present study. improve the efficacy and precision of the grouping algorithm. The threshold was standardized through checking the effects of repetitive experiments with different values. In GEE, the strategy was effectively practised using the code 'update Mask (ndwi.gte $(-0.3)$ and ndvi.lt $(0.2))$ ', where 'ndwi' and 'ndvi' are new bands included in the image by the previous step. Vegetation or nonwater pixels were removed through this operation ${ }^{34}$.

Further, surface-water area was calculated using machine learning algorithm, which enables the systems through training methods and classifies the images in a more accurate manner while identifying and classifying the pixels covered under different feature classes. In machine learning algorithm, the training samples were collected with geometry drawing tools through the interactive environment of GEE, using different spatial polygons with pixels of water bodies from lakes, rivers and ponds. Similarly, the training samples of other features were taken through polygons at different spatial locations over the study region of Telangana. These training samples of labelled classes were applied using the 'sample region' function to train the algorithm. The random forest (RF) machine learning algorithm was used to train the model. The algorithm was executed for estimating surface-water area and results compared with those of the above indices. RF is a supervised learning algorithm which generates decision trees on data samples, and then gets the forecast from each of them and finally selects the best solution by means of voting (https://amigolms.com). $\mathrm{RF}$ is the best learning algorithm in machine learning models by its structure and functionality. This has been proved in many applications in the agricultural sector in obtaining the expected results.

\section{Estimation of groundwater and rainfall}

The groundwater level data for 2013-2018 were collected from the Central Ground Water Board (CGWB; http://cgwb.gov.in/index.html; Table 2). The point data on groundwater measurements of borewells, dug wells and tube wells (Figure 3) were spatially interpolated by applying inverse distance weighting (IDW) technique in QGIS platform (v. 3.12.2). The IDW technique is widely used for groundwater interpolation as it provides output by emphasizing on neighbouring values with reasonable accuracy $^{35,36}$. In the present study, 667 (2013) to 1371 (2018) groundwater-level measurement point data were used. The extracted data on yearwise surface-area spread were compared with the annual rainfall data of the study region collected during the study period (https://data.gov.in/).

\section{Results and discussion}

The size and temporal dynamics of the water bodies at regional as well as global scale can be effectively 
monitored using RS datasets ${ }^{8,9}$. The number of studies in the field of surface-water estimation using RS has increased rapidly over the years. The 'basic search' in Web of Science (WoS) - a database of indexed journals using the keywords 'surface water' and 'remote sensing' in 'TOPIC' field showed that the last two decades (19982018) witnessed nearly sevenfold increase in terms of research articles published in various indexed journals (Figure 4).

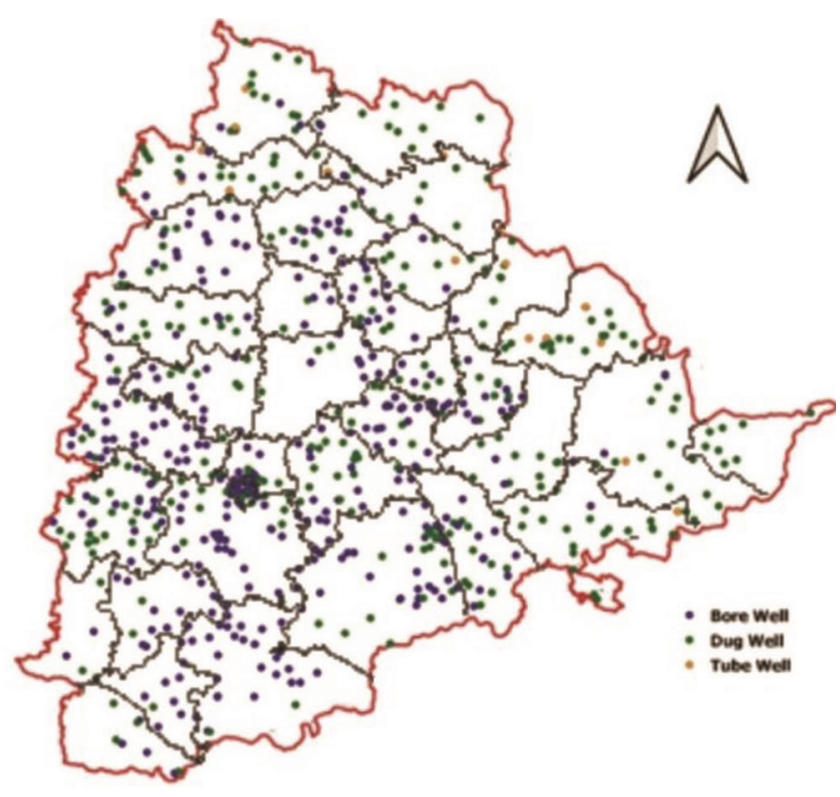

Figure 3. Spatial data of groundwater samples.

Table 2. Number of groundwater-level ( $\mathrm{m} \mathrm{bgl)}$ data points used in the present study

\begin{tabular}{lc}
\hline Year & $\begin{array}{c}\text { No. of groundwater-level points (dug wells/borewells/ } \\
\text { tube wells) }\end{array}$ \\
\hline 2013 & 667 \\
2014 & 748 \\
2015 & 759 \\
2016 & 995 \\
2017 & 1450 \\
2018 & 1371 \\
\hline
\end{tabular}

Table 3. Extent of surface-water area estimated using NDWI and mNDWI algorithms

\begin{tabular}{lll}
\hline & \multicolumn{2}{c}{ Area (sq. km) } \\
\cline { 2 - 3 } Year & NDWI & mNDWI \\
\hline 2013 & 2189.76 & 2189.76 \\
2014 & 1565.46 & 1564.41 \\
2015 & 1158.83 & 1158.83 \\
2016 & 1985.95 & 1985.90 \\
2017 & 1397.57 & 1397.57 \\
2018 & 2008.55 & 2008.51 \\
2019 & 1836.89 & 1836.89 \\
\hline
\end{tabular}

The extent of surface-water cover of Telangana during the post-monsoon season (2013-2019) was estimated by deploying two different indices, viz. mNDWI and NDWI using the multidate Landsat images. McFeeters ${ }^{13}$ introduced NDWI, which was largely used during the first decade of the 21 century ${ }^{37,38} . \mathrm{Xu}^{14}$ established the SWIR band that is able to reflect some indirect features of water; and consequently replaced the NIR band in NDWI with the SWIR band and proposed the mNDWI. Presently, it is widely recognized that mNDWI is more stable and reliable than NDWI. The SWIR band is less sensitive to the concentration of sediments and other optically active elements within waterbodies than the NIR band (Figure 5) ${ }^{4}$. Therefore, mNDWI and NDWI have been used in many recent studies ${ }^{34,39,40}$. Figure 6 shows the results of the algorithm developed with water indices for estimating the extent of waterbodies within the region of interest on the GEE code editor before and after execution.

\section{Extent of surface water}

Table 3 gives the extent of surface water estimated using both NDWI and mNDWI algorithms. The extent of surface-water cover ranged from 1158.83 (2015) to $2189.76 \mathrm{sq} . \mathrm{km}$ (2013) for both the indices during the study period. The results of the present study indicate that, there is no significant $(P<0.05)$ variation in the extent of surface-water cover estimated by the two methods (NDWI and mNDWI) in Telangana (Figure 7). The extent of surface water estimated using the RF algorithm showed a similar trend (Figure 8), as that by the two algorithms (NDWI and mNDWI), and there was no significant difference $(P<0.05)$. The GEE platform is a quick and feasible method for detecting annual changes in the extent of surface water, the assessment of which aids in monitoring the impacts of human activities on the waterbodies and their overall health ${ }^{34,41}$.

\section{Surface-water extent vis-a-vis rainfall and groundwater level}

This study showed that the extent of surface water had a significant positive correlation with rainfall $(r=0.85$; $P<0.05)$. The surface-water area estimate was highest in 2013 (2189.76 sq. km) in Telangana, when annual rainfall was $1348.7 \mathrm{~mm}$, and lowest during 2015 (1158.83 sq. km), when rainfall was also the lowest, i.e. $857.3 \mathrm{~mm}$ (Figure 9).

Table 4 gives the district-wise estimated area of annual surface-water extent of Telangana using RF algorithm. The highest surface-water extent was observed in districts like Nalgonda (533.63 sq. km), Mahabubnagar (336.92 sq. km) and Adilabad (303.06 sq. km) during 2013, and proportionately, the groundwater table also 
RESEARCH ARTICLES

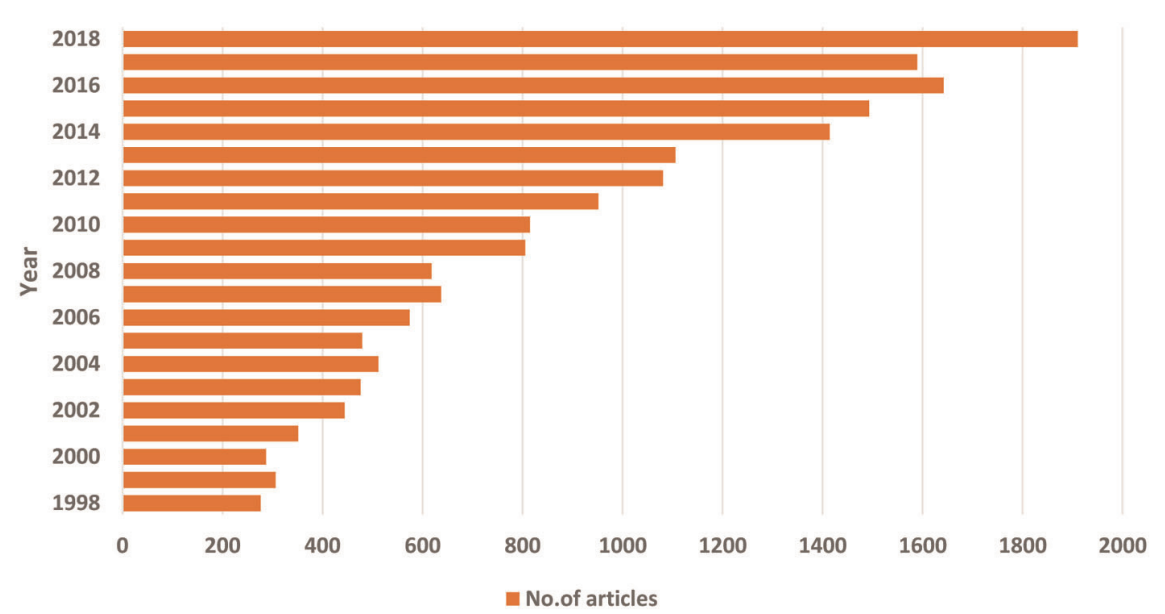

Figure 4. Research articles published on surface-water assessment using remote sensing.

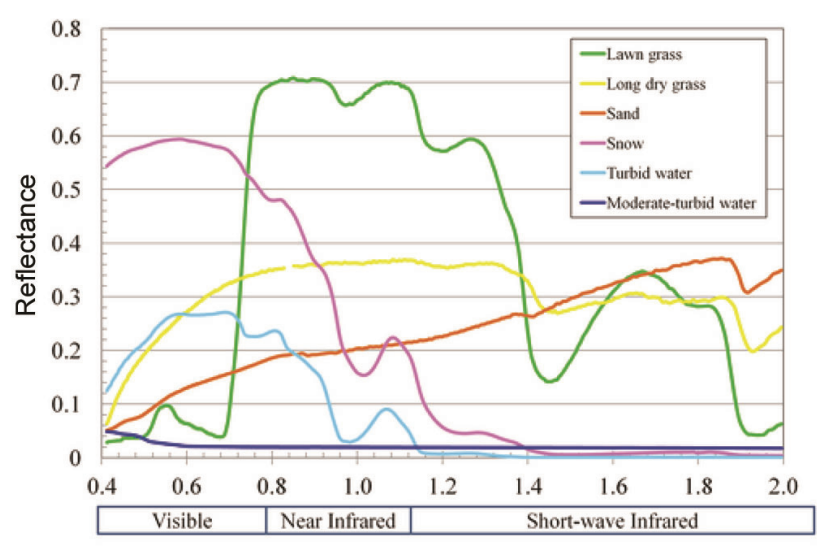

Wavelength $(\mu \mathrm{m})$

Figure 5. Reflectance of several typical land-cover objects.
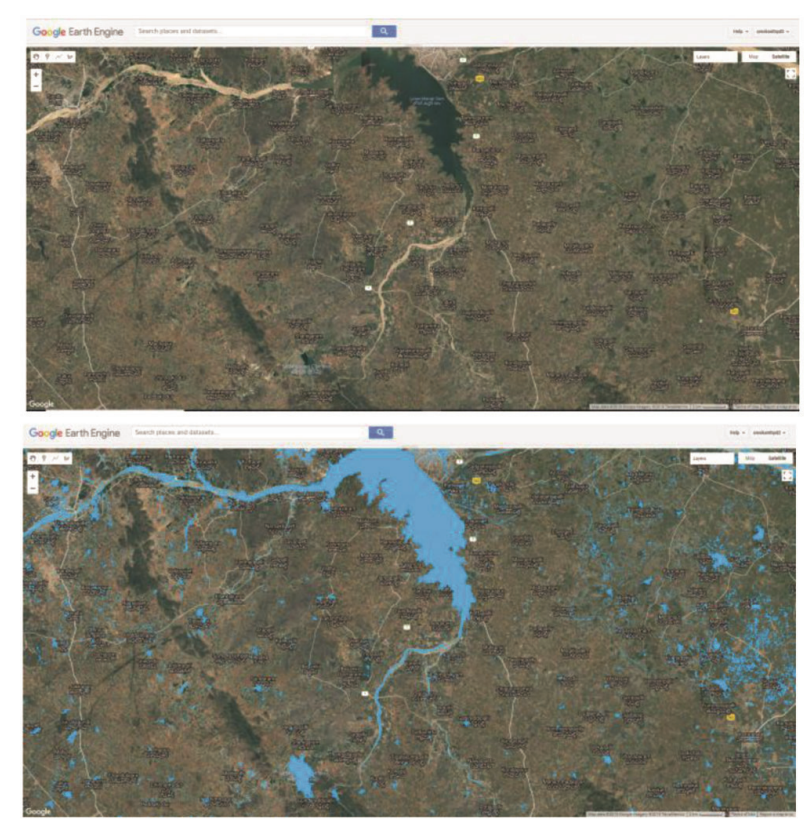

Figure 6. Results of normalized difference water index (NDWI) algorithm before and after execution.

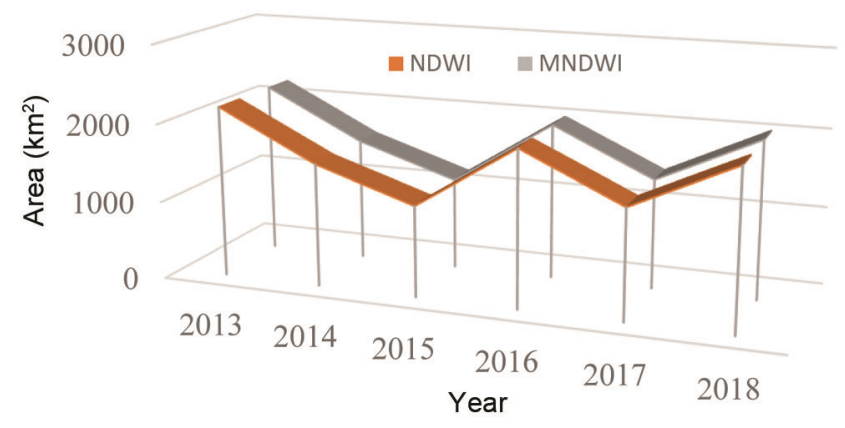

Figure 7. Trend between NDWI and mNDWI algorithms.

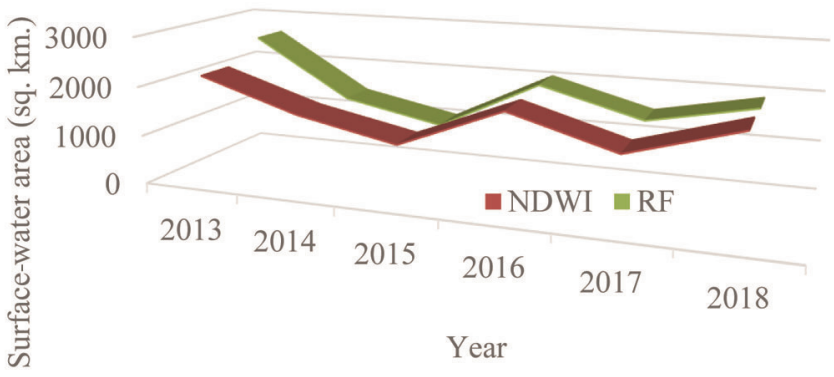

Figure 8. Trend between NDWI and RF algorithms.

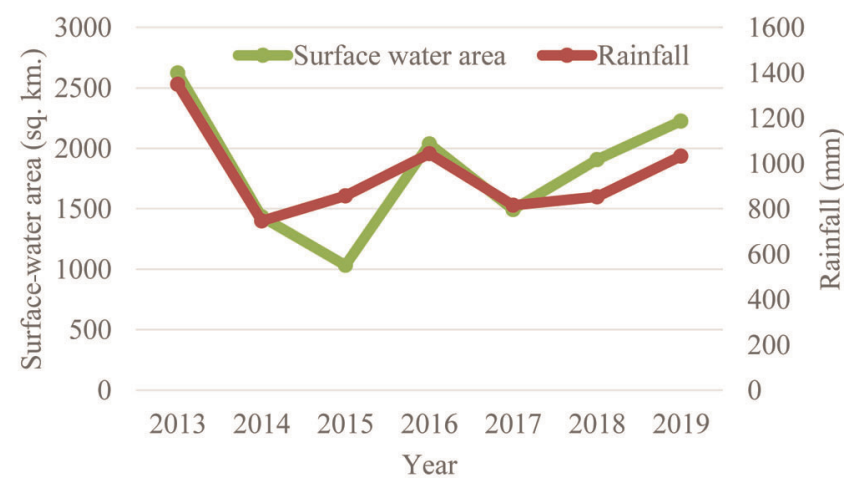

Figure 9. Comparison of surface-water area with rainfall data. 
Table 4. Surface-water area estimated using RF algorithm

\begin{tabular}{|c|c|c|c|c|c|c|c|c|c|c|c|c|}
\hline \multirow[b]{2}{*}{ Districts* } & \multicolumn{2}{|c|}{2013} & \multicolumn{2}{|c|}{2014} & \multicolumn{2}{|c|}{2015} & \multicolumn{2}{|c|}{2016} & \multicolumn{2}{|c|}{2017} & \multicolumn{2}{|c|}{2018} \\
\hline & GWL & $\mathrm{RF}$ & GWL & $\mathrm{RF}$ & GWL & $\mathrm{RF}$ & GWL & $\mathrm{RF}$ & GWL & $\mathrm{RF}$ & GWL & $\mathrm{RF}$ \\
\hline Adilabad & 3.12 & 303.06 & 4.15 & 192.08 & 4.68 & 151.60 & 4.83 & 333.10 & 4.75 & 197.68 & 4.21 & 259.91 \\
\hline Karimnagar & 3.59 & 237.04 & 7.1 & 125.20 & 8.7 & 98.42 & 4.77 & 220.91 & 7.25 & 144.44 & 5.84 & 227.27 \\
\hline Khammam & 3.26 & 298.36 & 4.84 & 138.67 & 4.67 & 140.06 & 4.64 & 80.19 & 3.59 & 159.36 & 5.26 & 229.74 \\
\hline Mahabubnagar & 9.55 & 336.92 & 13.25 & 299.77 & 16.81 & 206.17 & 14.42 & 425.83 & 11.97 & 241.75 & 5.71 & 206.66 \\
\hline Medak & 5.43 & 286.76 & 10.55 & 106.21 & 15.47 & 30.73 & 8.87 & 243.74 & 10.23 & 141.70 & 8.15 & 148.42 \\
\hline Nalgonda & 2.61 & 533.63 & 8.00 & 252.97 & 8.97 & 191.32 & 6.23 & 218.06 & 5.69 & 262.39 & 5.00 & 283.10 \\
\hline Nizamabad & 4.22 & 282.77 & 8.40 & 126.05 & 12.19 & 40.52 & 5.66 & 326.47 & 6.17 & 156.89 & 5.20 & 367.86 \\
\hline Rangareddy & 6.25 & 140.62 & 9.93 & 38.62 & 11.44 & 20.50 & 6.92 & 55.53 & 4.54 & 27.18 & 9.17 & 40.63 \\
\hline Warangal & 3.85 & 178.83 & 7.12 & 145.15 & 7.95 & 141.86 & 5.80 & 130.90 & 5.26 & 155.00 & 4.47 & 138.05 \\
\hline Hyderabad & 5.85 & 25.89 & 11.58 & 9.47 & 10.88 & 11.43 & 6.73 & 2.57 & 6.33 & 4.81 & 8.19 & 5.30 \\
\hline Total & 47.73 & 2623.88 & 84.92 & 1434.19 & 101.76 & 1032.61 & 68.87 & 2037.30 & 65.78 & 1491.20 & 61.20 & 1906.94 \\
\hline
\end{tabular}

*Estimation according to the pre-partition district boundaries. GWL, Groundwater level (m bgl); RF, Random forest algorithm surface-water area estimation (sq. km).
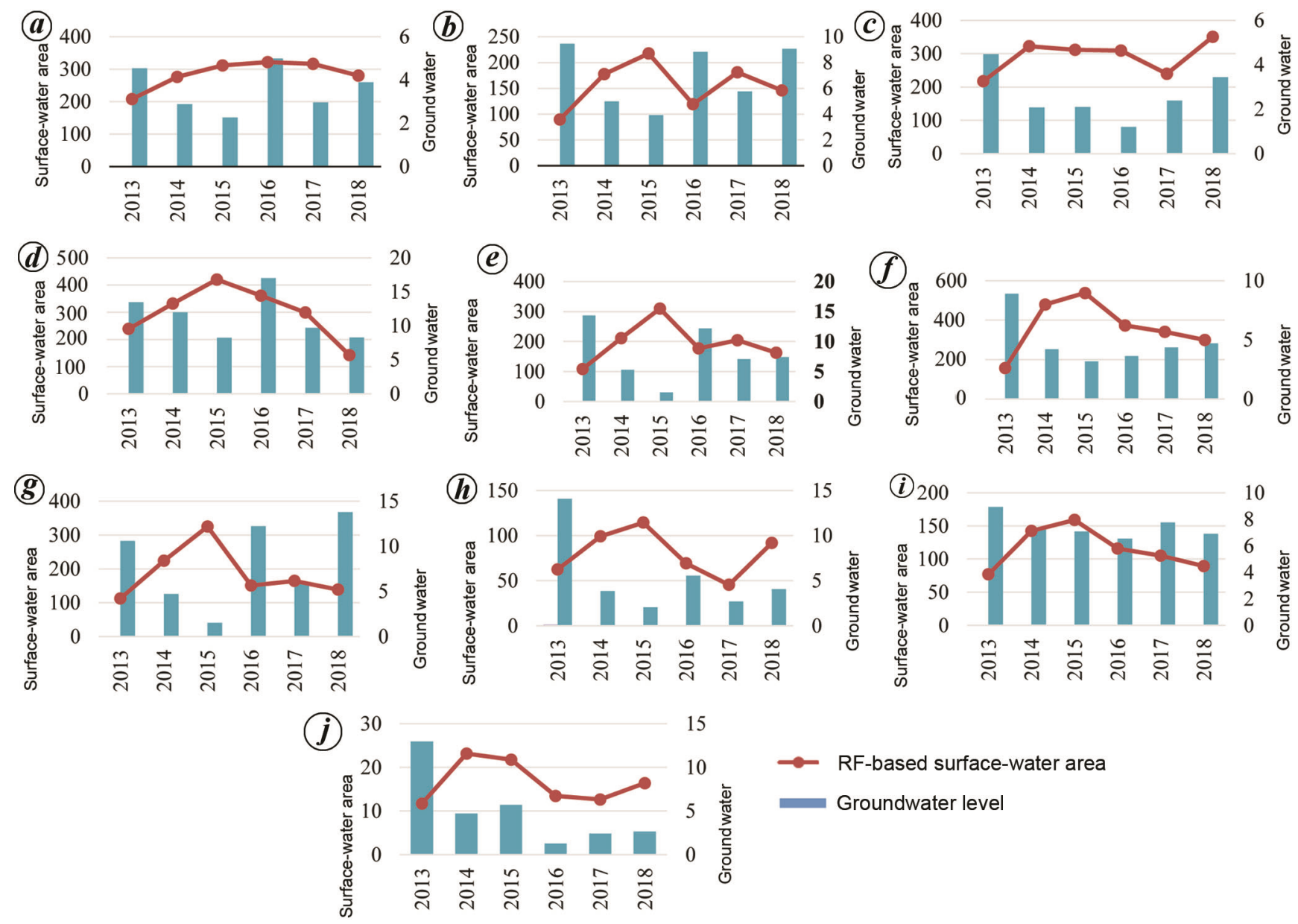

Figure 10. District-wise estimation of surface-water area (sq. km) using RF algorithm versus groundwater level. $\boldsymbol{a}$, Adilabad; $\boldsymbol{b}$, Karimnagar; $\boldsymbol{c}$, Khammam; $\boldsymbol{d}$, Mahabubnagar; $\boldsymbol{e}$, Medak; $\boldsymbol{f}$, Nalgonda; $\boldsymbol{g}$, Nizamabad; $\boldsymbol{h}$, Rangareddy; $\boldsymbol{i}$, Warangal; $\boldsymbol{j}$, Hyderabad.

rose in the above districts. The higher surface-water area of these districts may be attributed to the presence of a large number of water-storage structures like reservoirs, lakes and ponds. For instance, major reservoirs such as the Nagarjunasagar and Srisailam in the Krishna river basin fall in the Nalgonda and Mahabubnagar district respectively. Likewise, Sriram Sagar dam in the Godavari river basin falls in Adilabad district. The lowest value of 

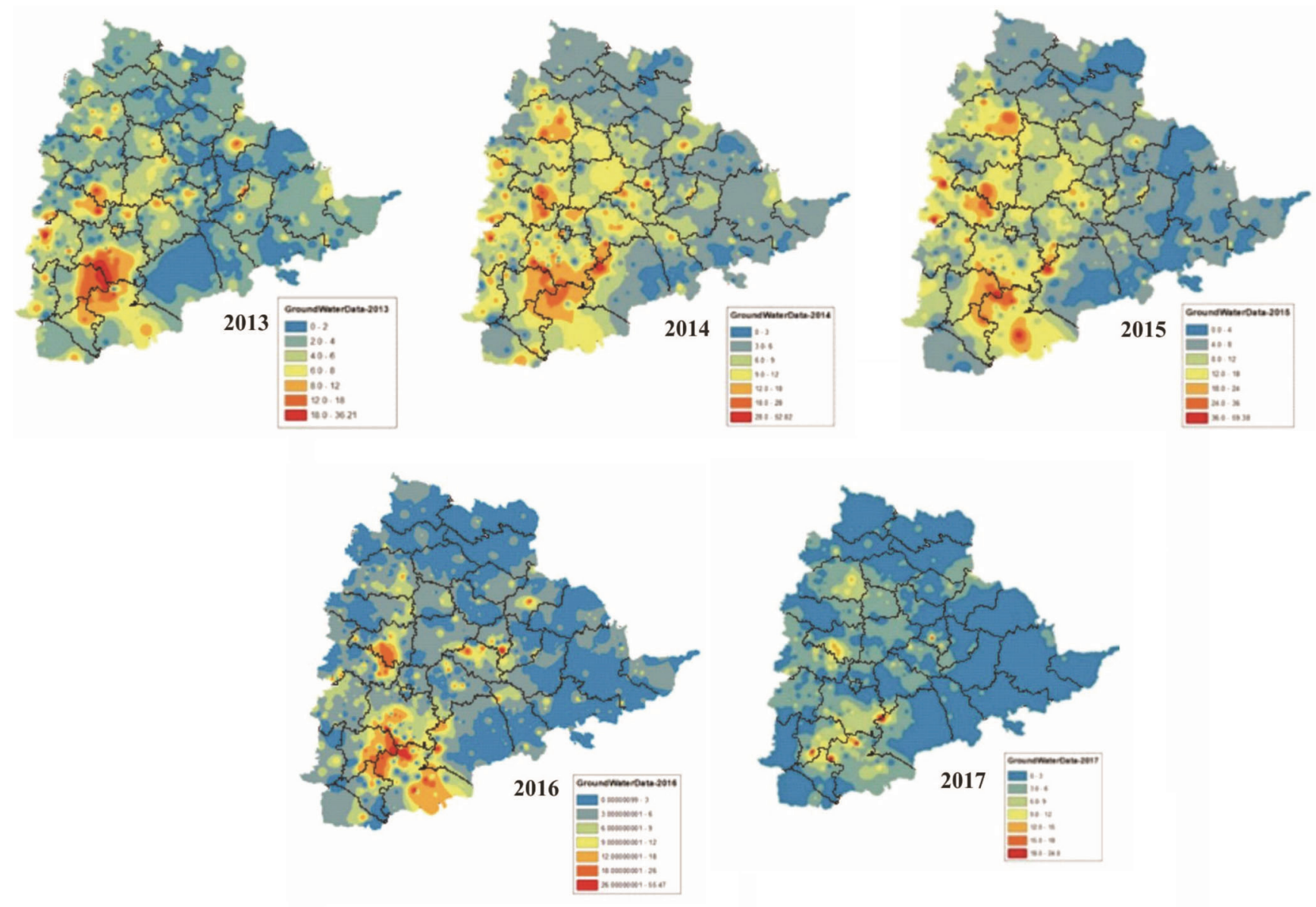

Figure 11. Trend of groundwater level in Telangana, India during 2013-2017.

the extent of surface water was observed in Hyderabad (25.89 sq. km), Rangareddy (140.62 sq. km) and Warangal $(178.83$ sq. km) districts. Hyderabad is one of the fastest growing mega cities in India in terms of its expansion on urban agglomeration along with Rangareddy district ${ }^{42}$. The estimated surface-water area declined during 2014 in all the districts due to less rainfall recorded in Telangana, i.e. $746.4 \mathrm{~mm}$ compared to the previous year (1348.7 mm). During 2016, good rainfall was received by the state (around $1043.4 \mathrm{~mm}$ ). Accordingly, the estimation of surface-water area also increased, and the groundwater recharge rose proportionately. A declining trend in both surface-water area and the groundwater table was noticed during 2017, due to a spell of drought. Again, there was an increasing trend of surface-water spread in both variables in 2018, compared to the previous year. Figure 10 depicts the extent of surfacewater area and groundwater level in the study area.

A comparison of the study results with CGWB groundwater level data using IDW interpolation method showed a positive correlation between groundwater level and estimated surface-water area $\left(R^{2}=0.86\right)$. From 2015 onwards, the extent of surface water was observed to increase due to higher rainfall, except in 2017, possibly because of drought. The increasing trend observed in the groundwater level from 2015 (Figure 11), could be partly attributed to Mission Kakatiya, a specialized water conservation project, launched by the Government of Telangana in 2015 (ref. 43), and which needs further systematic validation.

\section{Conclusion}

The rapid assessment of surface-water spread over a large area through remote sensing techniques offers huge scope in planning, monitoring and management of water resources. The present study estimates the district-wise surface-water spread of Telangana during 2013-2018 using the rapid GEE-based machine learning algorithm. The surface water availability-based algorithm could be effectively used for planning cropping patterns, assessing water restoration programmes, monitoring the flood events and to assess the effects of land-use pattern changes on natural water resources.

1. Du, N., Ottens, H. and Sliuzas, R., Spatial impact of urban expansion on surface water bodies - a case study of Wuhan, China. 
Landsc. Urban Plan., 2010, 94, 175-185; https://doi.org/10.1016/ j.landurbplan.2009.10.002.

2. Melendo, J. D. V., Water as a strategic resource: international cooperation in shared basins and geowater. J. Spanish Inst. Strat. Stud., 2015; http://revista.ieee.es/article/view/274.

3. Edokpayi, J. N., Odiyo, J. O. and Durowoju, O. S., Impact of wastewater on surface water quality in developing countries: a case study of South Africa. In Water Quality (ed. Hlanganani Tutu), Intech (open access), 2017, pp. 401-416; https://www. intechopen.com/books/water-quality/impact-of-wastewater-onsurface-water-quality-in-developing-countries-a-case-studyof-south-africa

4. Huang, C., Chen, Y., Zhang, S. and Wu, J., Detecting, extracting, and monitoring surface water from space using optical sensors: a review. Rev. Geophys., 2018, 56, 333-360; https://doi.org/ 10.1029/2018RG000598.

5. Karpatne, A., Khandelwal, A., Chen, X., Mithal, V., Faghmous, J. and Kumar, V., Global monitoring of inland water dynamics: state of the art, challenges and opportunities. In Computational Sustainability (eds Lassig, J., Kersting, K. and Morik, K.), Springer, Cham, 2016, vol. 645, pp. 121-147; https://doi.org/10.1007/978-3319-31858-5_7

6. Chang, N. B., Imen, S. and Vannah, B., Remote sensing for monitoring surface water quality status and ecosystem state in relation to the nutrient cycle: a 40-year perspective. Environ. Sci. Technol., 2015, 45, 101-166; https://doi.org/10.1080/10643389.2013. 829981

7. Gillespie, T. W., Foody, G. M., Rocchini, D., Giorgi, A. P. and Saatchi, S., Measuring and modelling biodiversity from space. Prog. Phys. Geogr., 2008, 32, 203-221; https://doi.org/10.1177/ 0309133308093606.

8. Schimel, D. S., Asner, G. P. and Moorcroft, P., Observing changing ecological diversity in the anthropocene. Front. Ecol. Environ., 2013, 11, 129-137; https://doi.org/10.1890/120111.

9. Ustin, S. L. and Gamon, J. A., Remote sensing of plant functional types. New Phytol., 2010, 186, 795-816; https://doi.org/10.1111/ j.1469-8137.2010.03284.x.

10. Wallace, J., Behn, G. and Furby, S., Vegetation condition assessment and monitoring from sequences of satellite imagery. Ecol. Manage. Restor., 2006, 7, 31-36; https://doi.org/10.1111/j.14428903.2006.00289.x.

11. Domenikiotis, C., Loukas, A. and Dalezios, N. R., The use of NOAA/AVHRR satellite data for monitoring and assessment of forest fires and floods. Nat. Hazards Earth Syst. Sci., 2003, 3, 115-128; https://doi.org/10.5194/nhess-3-115-2003.

12. Shrestha, R., Di, L., Yu, G., Shao, Y., Kang, L. and Zhang, B., Detection of flood and its impact on crops using NDVI - corn case. In second International Conference on Agro-Geoinformatics, Fairfax, VA, USA, 2013, pp. 200-204.

13. McFeeters, S. K., The use of the normalized difference water index (NDWI) in the delineation of open water features. Int. J. Remote Sensing, 1996, 17, 1425-1432; https://doi.org/10.1080/ 01431169608948714.

14. $\mathrm{Xu}, \mathrm{H}$., Modification of normalized difference water index (NDWI) to enhance open water features in remotely sensed imagery. Int. J. Remote Sensing, 2006, 27, 3025-3033.

15. Anand, A. et al., Mapping the potential areas for enclosure fish culture in tropical reservoirs: geo-spatial solutions for sustainable aquaculture expansion. Spat. Inf. Res., 2019, 27, 733-747; https://doi.org/10.1007/s41324-019-00294-w.

16. Acharya, T. D., Subedi, A. and Lee, D. H., Evaluation of water indices for surface water extraction in a Landsat 8 scene of Nepal. Sensors, 2018, 18, 1-15.

17. Mizuochi, H., Hiyama, T., Ohta, T. and Nasahara, K. N., Evaluation of the surface water distribution in north-central Namibia based on MODIS and AMSR series. Remote Sensing, 2018, 6, 7660-7682; https://doi.org/10.3390/rs6087660.
18. Akhtar, M. P., Roy, L. B. and Vishwakarma, K. M., Assessment of agricultural potential of a river command using geo-spatial techniques: a case study of Himalayan river project in Northern India. Appl. Water Sci., 2020, 10, 81; https://doi.org/10.1007/s13201020-1165-8.

19. Anand, A. et al., Assessing the water spread area available for fish culture and fish production potential in inland lentic waterbodies using remote sensing: a case study from Chhattisgarh state, India. Remote Sensing Appl.: Soc. Environ., 2020, 17, 100273; https:// doi.org/10.1016/j.rsase.2019.100273.

20. Das, R. T. and Pal, S., Exploring geospatial changes of wetland in different hydrological paradigms using water presence frequency approach in Barind Tract of West Bengal. Spat. Inf. Res., 2017, 25, 467-479; https://doi.org/10.1007/s41324-017-0114-6.

21. Wang, Z., Liu, J., Li, J. and Zhang, D. D., Multi-spectral water index (MuWI): a native 10-m multi-spectral water index for accurate water mapping on sentinel-2. Remote Sensing, 2018, 10, 1-21; https://doi.org/10.3390/rs10101643.

22. Soltanian, F. K., Abbasi, M. and Bakhtyari, H. R. R., Flood monitoring using NDWI and MNDWI spectral indices: a case study of Aghqala Flood-2019, Golestan Province, Iran. Int. Arch. Photogrammetry, Remote Sensing Spat. Inf. Sci., XLII-4/W18, 2010, 605-607; https://doi.org/10.5194/isprs-archives-XLII-4-W18-6052019.

23. DeVries, B., Huang, C., Armston, J., Huang, W., Jones, J. W. and Lang, M. W., Rapid and robust monitoring of flood events using Sentinel-1 and Landsat data on the Google Earth Engine. Remote Sensing Environ., 2020, 240, 111664

24. https://doi.org/10.1016/j.rse.2020.111664 (accessed on 10 December 2020).

25. MSME, Telangana - state profile 2015-16. MSME Development Institute, Hyderabad, 2016; http://dcmsme.gov.in/dips/state_wise_ dips/TS-Profile.pdf.

26. Environment Protection Training and Research Institute (EPTRI), State action plan on climate change for Telangana state. A report submitted to MOEF\&CC, GoI, 2017; http://moef.gov.in/ wp-content/uploads/2017/09/Telangana.pdf.

27. Shelestov, A., Lavreniuk, M., Kussul, N., Novikov, A. and Skakun, S., Exploring Google Earth Engine platform for big data processing: classification of multi-temporal satellite imagery for crop mapping. Front. Earth Sci., 2017, 7, 1-10; https://doi.org/ $10.3389 /$ feart.2017.00017.

28. United States Geological Survey (USGS), Landsat missions, Landsat 8, 2019; https://www.usgs.gov/land-resources/nli/landsat/ landsat-8?qt-science_support_page_related_con=0\#qt-science_ support_page_related_con.

29. Tucker, C. J., Red and photographic infrared linear combinations for monitoring vegetation. Remote Sensing of Environ., 1979, 8, 127-150; https://doi.org/10.1016/0034- 4257(79)90013-0.

30. Han-Qiu, X. A., Study on information extraction of water body with the modified normalized difference water index (mNDWI). J. Remote Sensing, 2005, 5, 589-595.

31. Ashraf, M. and Nawaz, R., A comparison of change detection analyses using different band algebras for Baraila wetland with NASA's multi-temporal landsat dataset. J. Geogr. Inf. Syst., 2015, 7, 1-19; https://doi.org/10.4236/jgis.2015.71001.

32. Ji, L., Zhang, L. and Wylie, B., Analysis of dynamic thresholds for the normalized difference water index. Photogr. Eng. Remote Sensing, 2009, 75, 1307-1317; https://doi.org/10.14358/PERS. 75.11 .1307

33. Karsli, F., Guneroglu, A. and Dihkan, M., Spatio-temporal shoreline changes along the southern Black Sea coastal zone. J. Appl. Remote Sensing, 2011, 5, 1-14; https://doi.org/10.1117/ 1.3624520 .

34. Wang, C., Jia, M., Chen, N. and Wang, W., Long-term surface water dynamics analysis based on landsat imagery and the Google Earth Engine platform: a case study in the Middle Yangtze river 
basin. Remote Sensing, 2018, 10, 1-18; https://doi.org/10.3390/ rs10101635.

35. Nistor, M. M., Rahardjo, H., Satyanaga, A., Hao, K. Z., Xiaosheng, Q. and Sham, A. W. L., Investigation of groundwater table distribution using borehole piezometer data interpolation: case study of Singapore. Eng. Geol., 2020, 271, 105590; https:// doi.org/10.1016/j.enggeo.2020.105590.

36. Jie, C., Hanting, Z., Hui, Q., Jianhua, W. and Xuedi, Z., Selecting proper method for groundwater interpolation based on spatial correlation. In Fourth International Conference on Digital Manufacturing and Automation, Qingdao, China, 2013, pp. 1192-1195; https://doi.org/10.1109/ICDMA.2013.282.

37. El Asmar, H. M. and Hereher, M. E., Change detection of the coastal zone east of the Nile delta using remote sensing. Environ. Earth Sci., 2011, 62, 769-777; https://doi.org/10.1007/s12665010-0564-9.

38. Nandi, D., Chowdhury, R., Mohapatra, J., Mohanta, K. and Ray, D., Automatic delineation of water bodies using multiple spectral indices. Int. J. Sci. Res. Sci., Eng. Technol., 2018, 4, 498-512.

39. Ji, L., Geng, X., Sun, K., Zhao, Y. and Gong, P., Target detection method for water mapping using Landsat 8 OLI/TIRS imagery. Water, 2015, 7, 794-817.
40. Acharya, T. D., Subedi, A., Huang, H. and Lee, D. H., Application of water indices in surface water change detection using Landsat imagery in Nepal. Sensors Mater., 2019, 31, 1429-1447.

41. Li, L., Vrieling, A., Skidmore, A., Wang, T. and Turak, E., Monitoring the dynamics of surface water fraction from MODIS time series in a Mediterranean environment. Int. J. Appl. Earth Observ. Geoinform., 2018, 66, 135-145; https://doi.org/10.1016/j.jag. 2017.11.007.

42. Wakode, H. B., Baier, K., Jha, R. and Azzam, R., Analysis of urban growth using Landsat TM/ETM data and GIS - a case study of Hyderabad, India. Arab. J. Geosci., 2014, 7, 109-121; https:// doi.org/10.1007/s12517-013-0843-3.

43. Sunday Guardian Live, Mission Kakatiya is a boon for farmers. 2017; https://www.sundayguardianlive.com/news/12244-missionkakatiya-boon-farmers.

Received 3 November 2020; revised accepted 10 February 2021

doi: $10.18520 / \mathrm{cs} / \mathrm{v} 120 / \mathrm{i} 9 / 1491-1499$ 